\title{
The Effects of Social Marginalization of Manja and Mana People: The Case of Zadi Woydda Kebele, Essera Woreda, Dawuro Zone, Southern Ethiopia
}

\author{
Sharku Melaku Meshido \\ Department of Civics and Ethical Studies, College of Social Sciences and Humanities, Wolaita Soddo University, \\ Wolaita Soddo, Southern Ethiopia
}

\begin{abstract}
The purpose of this study is assessing effect of social marginalization on 'Manja' and 'Mana' ethnic groups of Zadi Woyda Kebele in Issera Woreda, Dawuro Zone. The objective of the study was assessing the effect of social marginalization on 'Manja' and 'Mana' ethnic groups. To accomplish this objective, there were four basic questions. The study was also utilized the descriptive survey design along with mixed data collection method. The quantitative data was analysed by percentage and frequencies and the qualitative data was analysed by narration and qualitative descriptions. The data was collected from 37(Manja' and 'Mana') and 80 (mala ethnic groups) respondents. And 2 local elders and 2 cultural \& tourism officer were purposively selected. The quantitative data was analysed by using descriptive statistics such as frequency and percentage. The finding of study was indicated that the extent the Manja' and 'Mana' ethnic groups involvements in social affairs is restricted to the some extent of social activities but the Mala ethnic group dominance and their belief of keeping the statuesque of their social statues are high. The minority group ethnic (Manja' and 'Mana') educational participation in the school is very low due to their Children drop out, repeat the class as well as contentious absentees' and they cannot make marital relationship with "Mala" ethnic group in the study area. To minimize this problem, the study area administrative councils should prepare workshops, seminars, short term training, contentious discussion to create awareness, eradicating the traditional way of life of the minorities, and support the socio-economic, political and governmental activities and invite the interested NGOS' in the study areas.
\end{abstract}

Keywords: - Social Marginalization, Manja' and 'Mana', Social Exclusion, Marital Relationship.

DOI: $10.7176 /$ RHSS/10-13-06

Publication date:July $31^{\text {st }} 2020$

\section{INTRODUCTION}

\subsection{Background of the Study.}

Nowadays, federalism recommended as a good model to manage and govern ethnic pluralism in Ethiopia. It is conceived as good instrument that protects the rights of minority groups and promotes social security and state integration (Vander Beken, 2013). Social marginalization is multi-layered concept. It is "being outside the main stream of productive activity and/ or social reproductive activity" (Kagan, et. al, 2005). In line to this, Ethiopia contains many minority groups, consisting of hunters and craft workers, including the Wayto among the Amhara, the Waata among the Oromo, the Manjo among the Kafa and Dawuro, and so on. Social inequality is recognized to be the most devastating event that affects the stability of human life.

This condition coupled with poverty remains a chronic problem and still a threat to human race particularly those in the unfortunate end of the world. Studies show that social inequality (discrimination, stratification...etc.) is a common phenomenon in most societies Based on the form of social stratification takes, societies are portrayed as class systems, caste systems, caste like system etc. In most parts of south-western Ethiopia, farmers are thought of as primary social groups and administrators, on the other hand, artisans, and slaves are seen as secondary citizens. In the past, this stratification and hierarchy had serious implications of which access to economic resources (particularly land) and political offices were the most important ones (Abbay, 2009).

The population in the study area shares some of the characteristics of these common Cultural features of south-western Ethiopia in the sense that first, the society is differentiated Into various strata such as administrators/governors, farmers, artisans and foragers; second, Each of these strata is associated with specific occupations; and third, according to the traditional law in the society, people from different social background did not have equal access to land, political offices and social prestige. The study area is comprised of a society known as Dawro which is characterized by rigid hierarchic social organization or social stratification. According to this stratification, traditionally there are five ranked social groups, which form one type of social structure of the Dawro society. These are, ranked in descending order according to their level of social status: the Malla (the majority ethnic group), the Wogache (black smiths which is member of mala), and the Dencha (Tanners), the Manja and the Manna (potters). Social strata are created due to occupational and life style differences such as food item, work type and race. According to this social hierarchy, the social groups that are not part of Malla are discriminated in about every aspect of human interaction. (Ibid) 
The post-1991 period witnessed the introduction of an unprecedented political structure in the modern history of Ethiopia. The constitution of the Federal Democratic Republic of Ethiopia, which came into force in 1995, is built on the principle of accommodating diversity and the protection of the rights of the minority groups (FDRE constitution, 1995). As a matter of fact, the new constitution is adopted after the down fall of the dictatorial government of Derg, and consists of various human rights provisions and powers and benefits shared with regional states, but the federal constitution is not without drawbacks in its implementation (Abbay, 2009; Fiseha, 2007; Habtu, 2004; cited in Gebre slassie, 2016). The drastic changes that occurred in Ethiopia during the twentieth century have changed the livelihoods of minority groups consisting of hunters and craft workers. Some have given up their conventional subsistence activities, hunting or making crafts, and have begun farming. The relationships of these minorities with neighbouring majority groups are also changing (Gamst, 1979).

The studies of minority groups have been conducted from various perspectives, including approaches that focus on social structures such as castes and hierarchies, symbolic approaches that focus on pollution and fertility, and approaches that focus on patron-client relationships, and so on (Pankhurst, 1999). Most of these studies are based on the dominant perspective of the majority group, the farmers, and disregard the viewpoint of the minorities. Since the Ethiopian People's Revolutionary Democratic Front (EPRDF) came to power, the federal government has followed a policy of ethnic federalism. The new Constitution, enacted in 1994, acknowledges that all nations, nationalities, and peoples have an unconditional right to self-determination, including a right to secession. Article 39 defines the complex concept of nation, nationality and people as a group of people who have, or share in large measure, a common culture or similar customs, a mutually intelligible language, a belief in a common or related identity and a common psychological make-up, and who inhabit an identifiable, predominantly contiguous territory.

Based on this definition, affirmative measures for minority nationalities and peoples are introduced. The purpose of this affirmative action is to correct imbalance among the ethnic groups in the local administration. However, the combination of the federal system and the right to self-determination has created new political units, with their own political and cultural autonomy, which have caused problems and conflicts regarding the language used for education and administration in border areas. Intentionally or not, this provision further strengthens ethnicity as a political identity and as a vessel for "democratic rights" (Abbink, 1997: 172-173).

Marginalization and disparity among various ethnic groups in a particular nation might have impact on the development and competition in diverse aspects, such as cultural, linguistic, political, economic, educational, historic and social as well. Similarly the various impacts of marginalization faced on the minority 'Manja' and 'Mana' in the study area which initiated the researcher to provide prime concern for this issue among others.

\subsection{Statement of the Problem.}

Socio-economic inequalities within and between countries, that are judged to be unfair, unjust, and unnecessary and that systematically burden populations rendered vulnerability by underlying social structures and political, economic, and legal institutions (UNDP, 2000). The published book focused on the perspectives of the minorities. Minorities have reacted to, and whether they have accepted, the changes in their lifestyles and their relationships with neighbouring majority groups that occurred during the twentieth century. The relationships between these minorities and neighbouring majorities have been considered a discrimination or human rights issue. Several NGOs have initiated various campaigns to abolish discrimination (Pankhurst and Freeman (2003).

Although "ethnic minorities" and "indigenous people" have started movements to secure their indigenous rights, there are only a few movements of minority groups who do not even have indigenous rights, such as hunters and craft workers (e.g., Aneesa, 2000, Aneesa \& Ali, 2004). This article examines the kinds of changes experienced by minority groups and discusses their reactions using a case-study approach focused on the petition drives organized by one minority group, the Manjo, who are former hunters living in the Kafa and Sheka Zones of the Southern Nations, Nationalities, and People's Regional State (SNNPRs). Social inequality is recognized to be the most devastating event that affects the stability of human life. This condition coupled with poverty remains a chronic problem and still a threat to human race particularly those in the unfortunate end of the world. Studies show that social inequality (discrimination, stratification etc) is a common phenomenon in most societies (Berreman, 1981).

In most parts of south-western Ethiopia, farmers are considered as primary social groups, and administrators, but artisans, and slaves are seen as secondary citizens (Berhaneselassie, 1994). Traditionally, there are five ranked social groups, which form one type of social structure of the Dawuro society. These are ranked in descending order according to their level of social status: the'Malla' (the farming majority), the Wogache (blacksmiths), the 'Dencha' (tanners), the Manna (potters) and the 'Manja'. Social strata are created due to occupational and life style (food behavior) differences. According to this social hierarchy, the social groups that are not part of Malla are discriminated in about every aspect of human interaction (Dea, 2000).

The condition of marginalization is much worse for the two strata of the population such as 'Manja' and 'Manna'. A recent unpublished study conducted by Action Aid-Ethiopia revealed that the situation prevailing in 
the area appears to be much worse than the sorts found in conventional definition of marginalization (Dea, 2000). For instance, Flower defines marginalization as "the exclusion of certain populations from the process of decision-making that affects their wellbeing and prospects." (Flower, 1997). The situation prevailing in the study area is much more than just being excluded from decision making. It involves being looked down upon as a person of inferior category.

Marginalized people have poor control over their lives and the available resources. Their limited socioeconomic and political role is something that causes low-self-confidence, low self-esteem and various psychological problems. Being born and living in such an environment result in the lack of motive to change such conditions in each and every way (Burton, and Kagan, 2003). There are various marginalized groups in the study area that the study failed to investigate the effect of marginalization on socio-economic and political participation of those groups. That trivial group of individuals are Degella (tanners), Manja, Mana, Wogache and others as well. However, the highly segregated groups are of 'Manja' and 'Mana' people in the study area. Due to this, they participate less in socio-economic and political issues of the country and they are at low socioeconomic status. No research was conducted regarding to this issue, this study was intended to examine the effects of social marginalization of 'Manja' and 'Mana' ethnic groups on development of Issera Woreda in Dawuro Zone with the particular reference of Zadi Woyda Kebele and to suggest relevant recommendations on basis of the findings to overcome the identified problems.

\subsection{Objectives of the Study.}

\subsubsection{General Objective of the Study}

The general objective of this study was to examine the social marginalization of 'Manja' and 'Mana' ethnic groups in Zadi Woyida Kebele, Issera Woreda in Dawuro Zone, South Ethiopia.

\subsubsection{Specific Objectives of the Study.}

The specific objectives of the study:

$>$ To identify the effects of social marginalization of 'Manja' and 'Mana' ethnic groups in the study area.

$>$ To indicate the extent in which the 'Manja' and 'Mana' people in the study area are marginalized.

$>$ To point out the consequences of social marginalization of 'Manja' and 'Mana' ethnic groups in the study area.

$>$ To suggest the measures to be taken to minimize or avoid the social marginalization of 'Manja' and 'Mana' ethnic groups in the study area.

\subsection{Basic Research Questions.}

This study tried to answer the following basic questions:-

$>$ What are the effects of social marginalization of 'Manja' and 'Mana' ethnic groups in the study area?

$>$ To what extent the 'Manja' and 'Mana' ethnic groups in Zadiwoyida Kebele are marginalized?

$>$ What are the consequences of social marginalization of 'Manja' and 'Mana' ethnic groups in the study area?

$>$ What measures should be taken to minimize or avoid the marginalization of 'Manja' and 'Mana' ethnic groups in the study area?

\subsection{Significance of the Study.}

The findings of this study might be expected to have the practical implementation in Issera Woreda of Zadi Woyida Kebele. It may create awareness among the Woreda administrators, elites, and the community at large on the effect of social marginalization of marginalized groups on nation's development in general. The study also is expected to provide information to NGOs and other organizations those have been working on the minority groups in the area. The study can serve as stepping-stone for those who have an interest to conduct further in the area by including relatively larger number of target population.

\subsection{Scope of the Study.}

Geographically, the area of study is delimited to Zadi Woyda Kebele in Issera Woreda due to the time limitation and cost considerations. This study does not include all groups of people in Zadi Woyida Kebele of Issera Woreda, but those groups which are expected to provide essential information is included namely: the Woreda Culture and Tourism Officers, the Zadi Woyda Kebele local elders, who are nearby to the inhabiting area of 'Manja' and 'Mana' ethnic groups and the target groups of the study ('Manja' and 'Mana'). This study reviewed literature about 'Manja' and 'Mana' people's marginalization, the changing lifestyle of the 'Manja' and other variables mainly focused on the marginalization of the above mentioned two groups within society in the study area. 


\subsection{Limitation of the Study.}

During the study the researcher faced some short comes; such as shortage of financial resources, shortage of available reference materials, lack of supplementary research works in the study area, shortages of transportation services and the absence of internet technology were some of the limitations faced the researcher. However, these limitations happened, the researcher was tried to overcome it and conducted the study.

\section{RESEARCH METHOD}

\subsection{Research design.}

The main purpose of this study was to investigate the effects of social marginalization of Mana and Manja ethnic groups. To achieve this purpose, on the bases of basic questions and review of related literature descriptive survey design was used in this study. According to Creswell (2003), it is relatively inexpensive and takes little time to conduct. Moreover, it is recommended when gathering data about respondents, belief, opinion, scores, and outcomes. According to Best (2008:86), a descriptive study describes and interprets "what is" going to be done? It is concerned with conditions or relationships that exist, opinions that are held, process that are going on, effects that are evident or trends that are developing. According to Creswell (2003), such design also used to obtain general over view of the subject and to generalize study findings from sample to population. Thus, the use of descriptive survey design is found appropriate to this study.

\subsection{The Research Method.}

This study utilized mixed method approach through collecting and analysing both quantitative and qualitative data .The researcher initially used quantitative method through survey questionnaires and used semi-structured interviews to substantiate the quantitative data. The reason to use mixed methods approach for this study is such methods are advantageous to examine the same phenomenon from multiple perspectives and allow dipper dimensions to emerge (Cohen, 2007; Creswell, 2003:2012).

\subsection{Sources of Data and Target Population.}

The researcher was used primary sources of data for this study. In order to get relevant information about the effects of social marginalization of 'Manja' and 'Mana' ethnic groups on development of Issera Woreda in Dawuro Zone with particular reference Zadi Kebele. The primary information for this study was collected through questionnaire and interview. The target groups of this study was to provide necessary information for this study are educated and uneducated marginalized groups of 'Mana' and 'Manja', local Elders in Zadi Woyda Kebele nearby to those marginalized groups of 'Mana' and 'Manja' and the Woreda Culture and Tourism Officers.

\subsection{Sample size and Sampling techniques.}

Both simple random and purposive sampling techniques were used. Simple random sampling technique was employed to select 'Manja' and 'Mana' and the mala groups for questionnaires. The Woreda Culture and Tourism Officers and Local elder leader of Zadi Woyda Kebele were selected by using purposive sampling technique. From the total population of 120 , 37 ( 31\%) of 'Manja' and 'Mana' ethnic groups, the total population of 260, 80 (31\%) of 'Mala' ethnic groups, the total population of 10, $2(20 \%)$ of Woreda Culture and Tourism Officers and From the total population of 4 2(50\%) local elder leader of Zadi Woyda Kebele are taken as a target population as indicated table 1 bellow.

Table 1: Summary of Sample Size and Sampling Techniques

\begin{tabular}{|l|l|l|l|l|l|l|l|l|l|l|}
\hline \multirow{2}{*}{ No } & Target Groups & \multicolumn{2}{|l|}{$\begin{array}{l}\text { Total } \\
\text { Population }\end{array}$} & \multicolumn{3}{l|}{ Sample size } & \multirow{2}{*}{$\begin{array}{l}\text { Sampling } \\
\text { Techniques }\end{array}$} \\
\cline { 3 - 9 } & & $\mathbf{M}$ & $\mathbf{F}$ & $\mathbf{T}$ & $\mathbf{M}$ & $\mathbf{F}$ & $\mathbf{T}$ & & \\
\hline 1 & $\begin{array}{l}\text { Manja and Mana groups resident in Zadi } \\
\text { Woyda Kebele }\end{array}$ & 55 & 65 & 120 & 17 & 20 & 37 & 31 & $\begin{array}{l}\text { Simple random } \\
\text { Sampling }\end{array}$ \\
\hline 2 & $\begin{array}{l}\text { The Mala, groups resident in Zadi } \\
\text { Woyda Kebele }\end{array}$ & 110 & 150 & 260 & 30 & 50 & 80 & 31 & $\begin{array}{l}\text { Simple random } \\
\text { Sampling }\end{array}$ \\
\hline 3 & Woreda Culture and Tourism Officers & 7 & 3 & 10 & 1 & 1 & 2 & 20 & Purposive Sampling \\
\hline 4 & $\begin{array}{l}\text { Local edear leader of Zadi Woyda } \\
\text { Kebele }\end{array}$ & 4 & & 4 & 2 & & 2 & 50 & Purposive Sampling \\
\hline & Total & $\mathbf{1 7 6}$ & $\mathbf{2 1 8}$ & $\mathbf{3 9 4}$ & $\mathbf{5 0}$ & $\mathbf{7 1}$ & $\mathbf{1 2 1}$ & $\mathbf{3 1}$ & \\
\hline
\end{tabular}

Source: Own Survey of 2020. 


\subsection{Data Gathering Procedures}

After the preparation of data collection tools close-ended questionnaire, the researcher collected essential data through proper administration of the instruments. First, purpose of the study and the specific as well as general directions in the questionnaire is explained for the respondents by the researcher. Then, the prepared questionnaire is administered for 'Manja'and 'Mana' and mala ethnic groups and the Woreda Culture and Tourism Officers and the local elder leader are interviewed. Finally, the collected data is analysed and interpreted properly.

\subsection{Instruments of Data Collection}

The intended information for this study is obtained through two sets data gathering tools: questionnaire and interview. The researcher developed standardized questionnaire mainly focusing on selected variables and semistructured interview.

\subsubsection{Questionnaire}

The main reason for the preference of research questionnaire as contrasting to other tools is that, it is possible to reach relatively large research with in time limits and helps to achieve possible solutions to the basic research questions posed (Burns, 1994). Accordingly, this study is used questionnaires to collect data from Manja' and 'Mana' and mala ethnic groups. The set of questionnaires may be including 16 close ended items which are basically aimed at exploring the effects of social marginalization of Mana and Manja ethnic groups. Because according to James (1997), questionnaires are commonly used to gather data for descriptive survey. In addition, Somekh (2005) indicated that, close-ended questionnaires are easy to analyse statically as well as it allows the respondents to choose one option from the given alternatives that aligns with their view?

In line with this view, the close ended items are formulated. The first part of the questionnaire is designed to collect information on demographic characteristics of respondents, and the rest part of questionnaires consists of items and thought to elicit the effects of social marginalization of 'Manja' and 'Mana' ethnic groups on Zadi woyida Kebele in Issera Woreda. Then, the respondents are requested to indicate the extent of their feeling and opinions to each items ranging from strongly agree $=5$, agree $=4$, undecided $=3$, disagree $=2$ and strongly disagree $=1$.

\subsubsection{Interview.}

According to James (1997) interview allows collecting deep response which is not possible through any other means. Thus, the purpose of this interview was to gather additional information to enrich the questionnaires. The semi-structured interview questions were prepare in English and translated to "Dawurigna" language for more clarity of concept for respondents. The interview deals with Woreda Culture and Tourism Officers and local elder leader of Zadi Woyda Kebele.

\subsection{Method of Data Analysis.}

To carry out this research, the researcher used both qualitative and quantitative methods of data analysis on the basis of basic questions.

\subsubsection{Quantitative Data Analysis.}

The data which is gathered through questionnaire is analysed by using quantitative data analysis. The quantitative data collected through questionnaire is analysed by using tables, frequency and percentage.

\subsubsection{Qualitative Data Analysis.}

The data obtained through interview was analysed qualitatively. The qualitative data is first organized into meaningful information and the data is described both as expressed by interviewees and as understood by the researcher.

\subsection{Ethical Consideration.}

The study is started after fully discussed with the woreda and kebele administrations during the sensitization and mobilization trip on the issue of study and reached on consensus that the data or information from the study is available for the development of the woreda. The respondents are asked for verbal consent to participate in the study.

\section{RESULT AND DISCUSSION}

\subsection{Introduction}

This chapter presents the description of the sample population, analysis and interpretation of the data based on the information obtained through the questionnaires and Interviews. It consists of two parts, the first part concerned with the description of respondent's characteristics whereas; the second part deals with the analysis and interpretation of the main data. The purpose of this data was aimed to explore the effects of social marginalization of Manja and Mana ethnic groups in zadi woyda kebele of Issera woreda in South Ethiopia. To this end, the investigator developed data gathering tools that integrate various aspects of social marginalization 
of Manja and Mana ethnic groups in zadi woyda kebele of Issera woreda. For this purpose, thirty seven Manja and Mana ethnic groups and eighty mala ethnic groups for questionnaire are prepared, two local elder leaders and two experts of the woreda culture and tourism office are selected for interview. Totally 117 respondents were selected in the study area to perform the study.

The data is collected from a total of 117 respondents. To this end, a total of 117 copies of questionnaires are distributed, among this $117(100 \%)$ filled in and collected. Two office men and local elder leaders are interviewed. Finally, the research analyses is done based on the data obtained from the remaining $117(100 \%)$ of the questionnaires and interview results. Manja and Mana ethnic groups and mala ethnic group members responded to closed-ended questionnaire items. The closed-ended items computed and analyzed using table, frequency and percentage. In addition, items across each category are arranged under the five points liker scale. These five points scale range from strongly agree $=5$, agree $=4$, undecided $=3$, disagree $=2$ and strongly disagree $=1$. Besides, data from interview are qualitatively interpreted to validate the findings, means scores are calculated from the responses for the purpose of easy analysis and interpretation; the descriptive statistics such as frequency and percentage are used to summarize the findings.

Table 2. Demographic Characteristics of the Respondents

\begin{tabular}{|c|c|c|c|c|c|c|c|c|c|c|c|}
\hline \multirow[t]{2}{*}{ No } & \multirow{2}{*}{\multicolumn{2}{|c|}{ Variable }} & \multirow[t]{2}{*}{ Category } & \multicolumn{2}{|c|}{ Mana \& Manja } & \multicolumn{2}{|c|}{ Mala group } & \multicolumn{2}{|c|}{ Officer } & \multicolumn{2}{|c|}{ Eder leader } \\
\hline & & & & $\mathbf{N}$ & $\%$ & $\mathbf{N}$ & $\%$ & $\mathbf{N}$ & $\%$ & $\mathbf{N}$ & $\%$ \\
\hline \multirow[t]{3}{*}{1} & \multirow{3}{*}{\multicolumn{2}{|c|}{ Sex }} & Male & 17 & 46 & 38 & 47 & 1 & 50 & 2 & 100 \\
\hline & & & Female & 20 & 54 & 42 & 53 & 1 & 50 & & \\
\hline & & & Total & 37 & 100 & 80 & 100 & 2 & 100 & 2 & 100 \\
\hline \multirow[t]{5}{*}{2} & \multirow{5}{*}{\multicolumn{2}{|c|}{ Age }} & $20-30$ & 12 & 32 & 18 & 22 & & & & \\
\hline & & & $31-40$ & 20 & 54 & 43 & 54 & 2 & 100 & & \\
\hline & & & $41-50$ & 5 & 14 & 15 & 19 & & & 2 & 100 \\
\hline & & & Above 51 & & & 4 & 5 & & & & \\
\hline & & & Total & 37 & 100 & 80 & 100 & 2 & 100 & 2 & 100 \\
\hline \multirow{6}{*}{3} & \multirow{6}{*}{\multicolumn{2}{|c|}{$\begin{array}{l}\text { Educational } \\
\text { ground }\end{array}$}} & $\begin{array}{l}\text { Below } \\
\text { Elementary }\end{array}$ & 32 & 87 & 50 & 63 & & & & \\
\hline & & & Elementary & & & 5 & 6 & & & 2 & 100 \\
\hline & & & Secondary & 2 & 5 & 3 & 4 & & & & \\
\hline & & & Diploma & 3 & 8 & 8 & 10 & & & & \\
\hline & & & Degree & & & 14 & 17 & 2 & 100 & & \\
\hline & & & Total & 37 & 100 & 80 & 100 & 2 & 100 & 2 & 100 \\
\hline
\end{tabular}

Source: Own Survey of 2020.

Sex

Regarding to sex of Mana \& Manja ;Mala group, Office men and Eder leader as indicated on above table1item one, $17(46 \%)$ of Mana \& Manja ethnic groups are males and $20(54 \%)$ of them are females whereas $38(47 \%)$ of Mala ethnic groups are males and $42(53 \%)$ of them are females, $1(50 \%)$ and $1(50 \%)$ of Office men are males and females respectively and $2(100 \%)$ of local Eder leader are males. The majority 20(54\%) of Mana \& Manja ethnic groups respondents, $42(53 \%)$ of Mala ethnic groups and $1(50 \%)$ of Office men are females and $2(100 \%)$ of local Eder leader are males.

Age

Concerning the age of the respondents in table1 item two, 12 (32\%) Mana \& Manja between the ages of 20-30 years old, $20(54 \%)$ are between the ages of 31-40 years old, and 5(14\%) are between the ages of 41-50 years old. Regarding the ages of Mala ethnic groups 18 (22\%) of them are between the ages of 20-30 years old, 43 (54\%) of them are between the ages of 31-40 years old, 15(19\%) are between the ages of 41-50 years old and 4(5\%) are above 51 years old. Concerning the age of Office men 2(100\%) of them are between the ages of 31-40 years old and $2(100 \%)$ of local Eder leaders are ages of 41-50 years old. Regarding the ages of respondent's, majority 20 (54\%) Mana \& Manja, 43 (54\%) Mala ethnic groups, and 2 (100\%) Office men are between the ages of 31-40 years old. This implies that they are at adult level and matured enough to provide their decision.

Educational Background

When come to the educational background of the manja and mana ethnic group respondents, the above table 1 
item 3 shows $32(87 \%)$ of them are below elementary, $2(5 \%)$ of them are Secondary school level, and 3(8\%) of them are Diploma graduates. Concerning the mala ethnic group educational background, 50(63\%) of them are below elementary, $5(6 \%)$ of them are Elementary school, 3(4\%) of them are Secondary school level, 8(10\%) of them are diploma holders and 14(17\%) of them are degree holders. Regarding to the Office men and local Eder leader respondents, $2(100 \%)$ of the Office men respondent are degree holders and 2(100\%) of local Eder leader are Elementary school level. This indicates that the majority of the respondents $32(87 \%)$ of Manja and Mana ethnic groups, $25(83 \%)$ of management members and 3(100\%) are first degree holders and 2(67\%) of the school principals second degree holders respectively.

Table 3 .Questions Related to extent of the 'Manja' and 'Mana' ethnic group marginalization in study area.

\begin{tabular}{|c|c|c|c|c|c|c|c|c|c|c|c|c|}
\hline \multirow[t]{2}{*}{ No } & \multirow[t]{2}{*}{ Item } & \multirow[t]{2}{*}{ R.C } & \multicolumn{2}{|c|}{ S.A } & \multicolumn{2}{|c|}{ AG } & \multicolumn{2}{|c|}{ UD } & \multicolumn{2}{|c|}{ DA } & \multicolumn{2}{|c|}{ SDA } \\
\hline & & & $\mathbf{F}$ & $\%$ & $\mathbf{F}$ & $\%$ & $\mathbf{F}$ & $\%$ & $\mathbf{F}$ & $\%$ & $\mathbf{F}$ & $\%$ \\
\hline \multirow[t]{2}{*}{1} & \multirow{2}{*}{$\begin{array}{l}\text { The extent of Manja' and 'Mana' ethnic group's } \\
\text { involvement in social organization like ider and } \\
\text { iqub in the leader position with "Mala" ethnic } \\
\text { group were encouraged }\end{array}$} & M1 & & & & & & & 2 & 5 & 35 & 95 \\
\hline & & M2 & & & & & & & 2 & 3 & 78 & 97 \\
\hline \multirow[t]{2}{*}{2} & \multirow{2}{*}{$\begin{array}{l}\text { The extent of Manja' and 'Mana' ethnic group's } \\
\text { participation in the school education in Zadi } \\
\text { woyda kebele was high. }\end{array}$} & M1 & & & & & & & 17 & 46 & 20 & 54 \\
\hline & & M2 & & & & & & & 25 & 31 & 55 & 69 \\
\hline \multirow[t]{2}{*}{3} & \multirow{2}{*}{$\begin{array}{l}\text { The extent of Manja' and 'Mana' ethnic groups } \\
\text { making marital relationship with "Mala" ethnic } \\
\text { group in Zadi woyda kebele now day is possible }\end{array}$} & M1 & & & & & & & & & 37 & 100 \\
\hline & & M2 & & & & & & & & & 80 & 100 \\
\hline \multirow[t]{2}{*}{4} & \multirow{2}{*}{$\begin{array}{l}\text { The extent of Manja' and 'Mana' ethnic groups } \\
\text { social interaction like drinking coffee and eating } \\
\text { food with "Mala" ethnic group together now day } \\
\text { is possible }\end{array}$} & M1 & & & & & & & & & 37 & 100 \\
\hline & & M2 & & & & & & & & & 80 & 100 \\
\hline
\end{tabular}

Source: Own Survey of 2020.

Remember: R.C = respondent categories, S.A = Strongly Agree, A.G = Agree, U.D =

Undecided, D.A= Disagree, $\mathrm{SDA}=$ Strongly Disagree, $\mathrm{M} 1=$ Mana and Manja and M2 = Mala

Table 3 above presents the views of Mana, Manja and Mala ethnic group of Zadi woyda kebele on the extent of Manja' and 'Mana' ethnic group's involvement in social organization like ider and iqub in the leader position with "Mala" ethnic group are encouraged. A look at the table1 item one shows that, the majority of respondents $35(92 . \%)$ of mana and manja and 78(97\%) of Mala ethnic groups responded strongly disagreed and, $2(5 \%)$ of mana and manja and $2(3 \%)$ of Mala ethnic groups responded disagreed that the extent of Manja' and 'Mana' ethnic group's involvement in social organization like idir and iqub in the leader position with "Mala" ethnic group are encouraged. On the same table 2 above items two, the respondents are asked to rate either the extent of Manja' and 'Mana' ethnic group's participation in the school education in Zadi woyda kebele is high. In this regard, $17(46 \%)$ of mana and manja and 25(31\%) of Mala ethnic group responded disagree and 20(54\%) of mana and manja and 55(69\%) of Mala ethnic groups responded strongly disagreed.

On the same table 3 above items three, the respondents are asked to rate either the extent of Manja' and 'Mana' ethnic groups making marital relationship with "Mala" ethnic group in Zadiwoyda kebele now day is possible. In this regard, $37(100 \%)$ of mana and manja and $80(100 \%)$ of Mala" ethnic groups responded strongly disagreed. On the same table, 3 above items 4, the respondents are asked to rate either the extent of Manja' and 'Mana' ethnic groups social interaction like drinking coffee and eating food with "Mala" ethnic group together now day is possible. In this regard, $37(100 \%)$ of mana and manja and $80(100 \%)$ of Mala" ethnic group responded strongly disagreed. 
Table 4. Questions Related to consequence of the 'Manja' and 'Mana' ethnic group marginalization in study area.

\begin{tabular}{|c|c|c|c|c|c|c|c|c|c|c|c|c|}
\hline \multirow[t]{2}{*}{ No } & \multirow[t]{2}{*}{ Item } & \multirow[t]{2}{*}{ R.C } & \multicolumn{2}{|c|}{ S.A } & \multicolumn{2}{|c|}{ AG } & \multicolumn{2}{|c|}{ UD } & \multicolumn{2}{|c|}{$\overline{\text { DA }}$} & \multicolumn{2}{|c|}{ SDA } \\
\hline & & & $\mathbf{F}$ & $\%$ & $\mathbf{F}$ & $\%$ & $\mathbf{F}$ & $\%$ & $\mathbf{F}$ & $\%$ & $\mathbf{F}$ & $\%$ \\
\hline \multirow[t]{2}{*}{1} & \multirow{2}{*}{$\begin{array}{l}\text { The extent of Manja' and 'Mana' ethnic group's } \\
\text { involvement in social organization like ider and } \\
\text { iqub in the leader position with "Mala" ethnic } \\
\text { group were impossible practices. }\end{array}$} & M1 & 37 & 100 & & & & & & & & \\
\hline & & M2 & 80 & 100 & & & & & & & & \\
\hline \multirow[t]{2}{*}{2} & \multirow{2}{*}{$\begin{array}{l}\text { The extent of Manja' and 'Mana' ethnic group's } \\
\text { participation in the school education in Zadi } \\
\text { woyda kebele was continuously decreased and } \\
\text { their educational wastage in the school rose. }\end{array}$} & M1 & 22 & 59 & 15 & 41 & & & & & & \\
\hline & & M2 & 55 & 69 & 25 & 31 & & & & & & \\
\hline \multirow[t]{2}{*}{3} & \multirow{2}{*}{$\begin{array}{l}\text { The extent of Manja' and 'Mana' ethnic groups } \\
\text { making marital relationship with "Mala" ethnic } \\
\text { group in Zadi woyda kebele now day is } \\
\text { impossible and the "mana "are perceived as } \\
\text { sprites of "evil" }\end{array}$} & M1 & 37 & 100 & & & & & & & & \\
\hline & & M2 & 80 & 100 & & & & & & & & \\
\hline \multirow[t]{2}{*}{4} & \multirow{2}{*}{$\begin{array}{l}\text { The extent of Manja' and 'Mana' ethnic groups } \\
\text { social interaction like drinking coffee and eating } \\
\text { food together with "Mala" ethnic group now } \\
\text { day is impossible }\end{array}$} & M1 & 37 & 100 & & & & & & & & \\
\hline & & M2 & 80 & 100 & & & & & & & & \\
\hline
\end{tabular}

\section{Source: Own Survey of 2020.}

Remember: R.C = respondent categories, $S . A=$ Strongly Agree, A.G = Agree, U.D = Undecided, D.A= Disagree, $\mathrm{SDA}=$ Strongly Disagree, $\mathrm{M} 1=$ Mana and Manja and M2 = Mala.

A look at the table 4 item one, the respondents are asked to rate either the extent of Manja' and 'Mana' ethnic group's involvement in social organization like ider and iqub in the leader position with "Mala" ethnic group are impossible practices. 37(100\%) of mana and manja and 80(100\%) of "Mala" ethnic group responded strongly agree. This implies, there are high consequences of social marginalization on mana and manja ethnic groups in the study area. On the same table 4 above items 2, the respondents are asked to rate the extent of Manja' and 'Mana' ethnic group's participation in the school education in Zadi woyda kebele is continuously decreased and their educational wastage in the school rose. 22 (59\%) of mana and manja and 55(69\%) of Mala" ethnic groups responded strongly agree, 15(41\%) of mana and manja and25 (31\%) of Mala" ethnic group have agreed.

On the same table 4 above items 5, the respondents are asked to rate either the extent of Manja' and 'Mana' ethnic groups making marital relationship with "Mala" ethnic group in Zadi woyda kebele now day is impossible and the wrong outlook of "mana "ethnic group as sprites of "evil". In this regard, 37(100\%) of mana and manja $80(100 \%)$ of Mala responded strongly agree. This shows the social marginalization of mana and manja ethnic group is high social impacts on them. On the same table 5 above items 4 , the respondents are asked to rate either the extent of Manja' and 'Mana' ethnic groups social interaction like drinking coffee and eating food together with "Mala" ethnic group now day is impossible in Zadi woyda kebele. In this regard, 37(100\%) of mana and manja $80(100 \%)$ of Mala responded strongly agree. This shows the social marginalization of mana and manja ethnic group in the study area is high consequences on social status of those minority groups. 
Table 5. Questions Related to Factors for 'Manja' and 'Mana' ethnic group marginalization in study area.

\begin{tabular}{|c|c|c|c|c|c|c|c|c|c|c|c|c|}
\hline \multirow[t]{2}{*}{ No } & \multirow[t]{2}{*}{ Item } & \multirow[t]{2}{*}{ R.C } & \multicolumn{2}{|c|}{ S.A } & \multicolumn{2}{|c|}{$\mathbf{A G}$} & \multicolumn{2}{|c|}{ UD } & \multicolumn{2}{|c|}{ DA } & \multicolumn{2}{|c|}{ SDA } \\
\hline & & & $\mathbf{F}$ & $\%$ & $\mathbf{F}$ & $\%$ & $\mathbf{F}$ & $\%$ & $\mathbf{F}$ & $\%$ & $\mathbf{F}$ & $\%$ \\
\hline \multirow[t]{2}{*}{1} & \multirow{2}{*}{$\begin{array}{l}\text { The Manja' and 'Mana' ethnic group's } \\
\text { misunderstanding of them as minority group } \\
\text { naturally and their no need for change. }\end{array}$} & M1 & 37 & 100 & & & & & & & & \\
\hline & & M2 & 37 & 100 & & & & & & & & \\
\hline \multirow[t]{2}{*}{2} & \multirow{2}{*}{$\begin{array}{l}\text { The extent of "Mala" ethnic group dominance } \\
\text { and the belief of Manja' and 'Mana' ethnic group } \\
\text { to keep up their statuesque Zadi woyda kebele. }\end{array}$} & M1 & 22 & 59 & 11 & 30 & 4 & 11 & & & & \\
\hline & & M2 & 55 & 69 & 20 & 25 & 5 & 6 & & & & \\
\hline \multirow[t]{2}{*}{3} & \multirow{2}{*}{$\begin{array}{l}\text { The extent of Manja' and 'Mana' ethnic group's } \\
\text { less working habit, poor nutrition and sanitation } \\
\text { practices in Zadi woyda kebele was major one. }\end{array}$} & M1 & 37 & 100 & & & & & & & & \\
\hline & & M2 & 80 & 100 & & & & & & & & \\
\hline \multirow[t]{2}{*}{4} & \multirow{2}{*}{$\begin{array}{l}\text { The extent of Manja' and 'Mana' ethnic groups } \\
\text { not adjusting themselves with the changing social } \\
\text { status of the environment in the global world }\end{array}$} & M1 & 37 & 100 & & & & & & & & \\
\hline & & M2 & 37 & 100 & & & & & & & & \\
\hline
\end{tabular}

Source: Own Survey of 2020.

Remember: R.C $=$ respondent categories, $S . A=$ Strongly Agree, A.G $=$ Agree, U.D = Undecided, D.A= Disagree, $\mathrm{SDA}=$ Strongly Disagree, $\mathrm{M} 1=$ Mana and Manja and M2 = Mala.

Table 6. Questions Related to Factors for 'Manja' and 'Mana' ethnic group marginalization in the study area.

\begin{tabular}{|c|c|c|c|c|c|c|c|c|c|c|c|c|}
\hline \multirow[t]{2}{*}{ No } & \multirow[t]{2}{*}{ Item } & \multirow[t]{2}{*}{ R.C } & \multicolumn{2}{|c|}{ S.A } & \multicolumn{2}{|c|}{$\mathbf{A G}$} & \multicolumn{2}{|c|}{ UD } & \multicolumn{2}{|c|}{ DA } & \multicolumn{2}{|c|}{ SDA } \\
\hline & & & $\mathbf{F}$ & $\%$ & $\mathbf{F}$ & $\%$ & $\mathbf{F}$ & $\%$ & $\mathbf{F}$ & $\%$ & $\mathbf{F}$ & $\%$ \\
\hline \multirow[t]{2}{*}{1} & \multirow{2}{*}{$\begin{array}{l}\text { The Manja' and 'Mana' ethnic group's } \\
\text { misunderstanding of them as minority group } \\
\text { naturally and their no need for change. }\end{array}$} & M1 & 37 & 100 & & & & & & & & \\
\hline & & M2 & 37 & 100 & & & & & & & & \\
\hline \multirow[t]{2}{*}{2} & \multirow{2}{*}{$\begin{array}{l}\text { The extent of "Mala" ethnic group dominance } \\
\text { and the belief of Manja' and 'Mana' ethnic group } \\
\text { to keep up their statuesque Zadi woyda kebele. }\end{array}$} & M1 & 22 & 59 & 11 & 30 & 4 & 11 & & & & \\
\hline & & M2 & 55 & 69 & 20 & 25 & 5 & 6 & & & & \\
\hline \multirow[t]{2}{*}{3} & \multirow{2}{*}{$\begin{array}{l}\text { The extent of Manja' and 'Mana' ethnic group's } \\
\text { less working habit, poor nutrition and sanitation } \\
\text { practices in Zadi woyda kebele was major one. }\end{array}$} & M1 & 37 & 100 & & & & & & & & \\
\hline & & M2 & 80 & 100 & & & & & & & & \\
\hline 4 & $\begin{array}{l}\text { The extent of Manja' and 'Mana' ethnic groups } \\
\text { not adjusting themselves with the changing social } \\
\text { status of the environment in the global world }\end{array}$ & M1 & 37 & 100 & & & & & & & & \\
\hline
\end{tabular}

\section{Source: Own Survey of 2020.}

Remember: R.C = respondent categories, $S . A=$ Strongly Agree, A.G = Agree, U.D = Undecided, D.A= Disagree, $\mathrm{SDA}=$ Strongly Disagree, $\mathrm{M} 1=$ Mana and Manja and M2 = Mala.

A look at the table 6 above item one, the respondents were asked to rate either extent of "Mala" ethnic group dominance or the belief of Manja' and 'Mana' ethnic group to keep up their statuesque in Zadi woyda kebele is among the factors. $37(100 \%)$ of mana and manja and 80(100\%) of "Mala" ethnic groups responded strongly agree. This implies that the internal push of mana and manja ethnic groups' high influence in the study area. On the same table 3 above items 2, the respondents are asked to rate the extent of "Mala" ethnic group dominance and the belief of Manja' and 'Mana' ethnic groups to keep up their statuesque in Zadi woyda kebele. $22(59 \%)$ of mana and manja and 55(69\%) of Mala" ethnic groups responded strongly agree, 15(41\%) of mana and manja and25 (31\%) of Mala" ethnic group have agreed.

On the same table 6 above items 3, the respondents are asked to rate either the extent of Manja' and 'Mana' ethnic group's less working habit, poor nutrition and sanitation practices in Zadi woyda kebele is among the factors. In this regard, 37(100\%) of mana and manja 80(100\%) of Mala responded strongly agree. This shows the way of life of mana and manja has its own contribution for social marginalization. On the same table 3 above items 4, the respondents were asked to rate either the extent of Manja' and 'Mana' ethnic groups not adjusting themselves with the changing social status of the environment in the global world now day in Zadi woyda kebele. In this regard, 37(100\%) of mana and manja 80(100\%) of Mala responded strongly agree. This shows the social marginalization of mana and manja ethnic groups in the study area was highly influenced by internal dominated factors. 
Table 7.Questions Related to Measures should be taken to minimize the Marginalization of 'Manja' and 'Mana' Ethnic Groups in the Study Area.

\begin{tabular}{|c|c|c|c|c|c|c|c|c|c|c|c|c|}
\hline \multirow[t]{2}{*}{ No } & \multirow[t]{2}{*}{ Item } & \multirow[t]{2}{*}{ R.C } & \multicolumn{2}{|c|}{ S.A } & \multicolumn{2}{|c|}{$\mathbf{A G}$} & \multicolumn{2}{|c|}{ UD } & \multicolumn{2}{|c|}{ DA } & \multicolumn{2}{|c|}{ SDA } \\
\hline & & & $\mathbf{F}$ & $\%$ & $\mathbf{F}$ & $\%$ & $\mathbf{F}$ & $\%$ & $\mathbf{F}$ & $\%$ & $\mathbf{F}$ & $\%$ \\
\hline \multirow[t]{2}{*}{1} & \multirow{2}{*}{$\begin{array}{l}\text { Creating awareness among Manja' and 'Mana' } \\
\text { ethnic group's to update their misunderstanding of } \\
\text { themselves as minority group naturally and } \\
\text { pushing them to need for change. }\end{array}$} & M1 & 37 & 100 & & & & & & & & \\
\hline & & M2 & 37 & 100 & & & & & & & & \\
\hline \multirow[t]{2}{*}{2} & \multirow[b]{2}{*}{$\begin{array}{l}\text { Introducing the change agenda within Zadi woyda } \\
\text { kebele to reduce the extent of "Mala" ethnic group } \\
\text { dominance and to eradicate the traditional belief of } \\
\text { Manja' and 'Mana' ethnic group to keep up their } \\
\text { statuesque. }\end{array}$} & M1 & 37 & 100 & & & & & & & & \\
\hline & & M2 & 80 & 100 & & & & & & & & \\
\hline \multirow[t]{2}{*}{3} & \multirow{2}{*}{$\begin{array}{l}\text { Improving the extent of Manja' and 'Mana' ethnic } \\
\text { group's less working habit, and traditional way of } \\
\text { life in Zadi woyda kebele. }\end{array}$} & M1 & 37 & 100 & & & & & & & & \\
\hline & & M2 & 80 & 100 & & & & & & & & \\
\hline 4 & $\begin{array}{l}\text { Building the capacity of Manja' and 'Mana' } \\
\text { ethnic groups to adjust themselves with the rapidly } \\
\text { changing social status of the environment in the } \\
\text { global world }\end{array}$ & M1 & 37 & 100 & & & & & & & & \\
\hline
\end{tabular}

Source: Own Survey of 2020.

Remember: R.C $=$ respondent categories, $S . A=$ Strongly Agree, $A . G=$ Agree, U.D =

Undecided, D.A= Disagree, $\mathrm{SDA}=$ Strongly Disagree, $\mathrm{M} 1=$ Mana and

Manja and M2 = Mala.

A look at the table 7 above item one, the respondents are asked to rate either Creating awareness among Manja' and 'Mana' ethnic group's to update their misunderstanding of themselves as minority group naturally and pushing them to need for change among the strategies to be taken, All of the respondents $37(100 \%)$ of mana and manja and $80(100 \%)$ of "Mala" ethnic groups responded strongly agree, Introducing the change agenda within Zadi woyda kebele to reduce the extent of "Mala" ethnic group dominance and to eradicate the traditional belief of Manja' and 'Mana' ethnic groups to keep up their statuesque by preparing themselves towards the changing environment among the strategies should be taken, the majority $22(59 \%)$ of mana and manja and 55(69\%) of Mala" ethnic groups have strongly agreed, improving the extent of Manja' and 'Mana' ethnic group's less working habit, and traditional way of life in Zadi woyda kebele. Among the strategies should be taken , the majority $22(59 \%)$ of mana and manja and 55(69\%) of Mala" ethnic groups have strongly agreed , building the capacity of Manja' and 'Mana' ethnic groups to adjust themselves with the rapidly changing social status of the environment in the global world is among the strategies should be taken .

\section{CONCLUSIONS AND RECOMMENDATIONS}

\subsection{Conclusion.}

The study was designed to explore the effects of social marginalization of manja and mana ethnic groups in zadi woyda kebele of Issera woreda in Southern Ethiopia. The finding indicated that the extent of the Manja' and 'Mana' ethnic group involvements on social affairs is restricted to the some extent of social activities, the extent of Mala ethnic group dominance and their belief of keeping the statuesque of their social statues are high ,the minority group (Manja' and 'Mana' ethnic group) educational participation in the school is low due to their Children drop out ,repeat on as well as contentious absentees' and the mana and manja ethnic groups cannot make marital relationship with "Mala" ethnic group in Zadi woyda kebele now day and even can't make the "maja" with "mana" which indicated the highly marginalization of the group in the study area.

The finding indicated that the consequences of social marginalization of 'Manja' and 'Mana' ethnic groups in the study area ; their participation on social activities is restricted, making marital relationship with the other ethnic group is impossible, they are involved simple and routine tasks which resulted on their poor economic status of the group in the study area. The finding indicated that among the influencing factors for social marginalization of Manja' and 'Mana' ethnic group's; "Mala" ethnic group dominance and the belief of Manja' and 'Mana' ethnic group to keep up their existing social statuesque, the extent of Manja' and 'Mana' ethnic group's less working habit, poor nutrition and sanitation practices, extent of Manja' and 'Mana' ethnic groups not adjusting themselves with the changing social status of the environment in the global world now day in Zadiwoyda kebele among the major factors for social marginalization in the study area.

The study indicated that the possible strategies to be taken to minimize the problem in the study area ; Creating awareness among Manja' and 'Mana' ethnic group's to update their misunderstanding of themselves as minority group naturally and pushing them to need for change, Introducing the change agenda within Zadi 
woyda kebele to reduce the extent of "Mala" ethnic group dominance and to eradicate the traditional belief of Manja' and 'Mana' ethnic group to keep up their statuesque by preparing themselves towards the changing environment, improving the extent of Manja' and 'Mana' ethnic group's less working habit, and traditional way of life in Zadi woyda kebele and building the capacity of Manja' and 'Mana' ethnic groups to adjust themselves with the rapidly changing social status of the environment in the global world is among the strategies should be taken .

\subsection{Recommendations}

4.2.1. Recommendations for Issera woreda Administrative council and Zadi woyda kebele Administration.

$>$ The zadi woyda kebele administration should prepare the awareness creation program me, experience sharing practices, democratic thing which should participate the minority groups on the top managerial position, should take administrative action to fill the gap of the disadvantaged minority group, motivate the educational participation of the minorities children's, and should make continuous support and smooth relationship to eradicate the backward thinking and practices of the Mana and Manja groups . Furthermore the zadi woyda kebele administration should assure the constitutional rights of the Mana and Manja ethnic group.

\subsubsection{Recommendations for mana and manja ethnic group at Zadi woyda kebele.}

$>$ The educated Mana and Manja ethnic group should Create awareness among Manja' and 'Mana' ethnic group's to update their misunderstanding of themselves as minority group naturally, push them to need for change by introducing the change agenda, to reduce the eradicate the traditional belief of Manja' and 'Mana' ethnic group to keep up their social statuesque supporting them to prepare themselves towards the changing environment, they should improve the extent of their less working habit, and traditional way of life, building their capacity to adjust themselves with the rapidly changing social status of the environment in the global world were recommended .

\subsubsection{Recommendations for NGOS and The interested voluntary groups.}

$>$ On the global world now days social marginalization almost all in the country gating its lasting stage. But in the developing countries like Ethiopia it is still now the existing serious problems in the areas like the zadi woyda kebele. It is recommended that the NGOS and other interested civic societies of welfare organization which is mission is related to in the areas of humanitarian action strongly invited to work with the kebele to capacitate the Mana and Manja ethnic groups .

$>$ Finally, to better address the problems, it can be suggested that further studies need to be conducted in this area with regard to social marginalization of Mana and Manja ethnic group in zadi woyda kebele of Issera Woreda.

\section{REFERENCES}

Abbink,J. (1997). Ethnicity and Constitutionalism in Contemporary Ethiopia. Journal of Africa Law 41: 159-174. AneesaKassa (2000). When will we be People as well? Social Identity and the Politics of Cultural Performance: The Case of the Waata Oromo of East and Northeast Mrica. Social Identities 6 \{2): 189-206.

AneesaKassam \& Ali Balla, (2004). Marginalization of the Waara Oromo Hunter Gatherers of Kenya: Insider and Outsider Perspectives. Africa 74 (2): 194-216.

Assefa, Mekuria (2015).AnInvestigationofInterculturalRelationthroughAdultEducation:In the Case of Enewary and Surrounding Communities in North Shewa Zone of the Amhara National Regional State.

BehailuAbebe\& Data Dea (2003). Dawro. In Freeman, D. \& A. Pankhurst \{eds.), Peripheral People: The Excluded Minorities of Ethiopia. Asmara: The Red Sea Press, pp. 105-131.

Berhaneselassie Tadesse (1994). The Wolita Conception of Inequality. In the Preceding of 11 International Conference on Ethiopia. Vol II.

Berreman, G.D. (1981). Social Inequality: A Cross-cultural analysis. In G.D Berreman, (ed.) Social inequality: comparative and developmental approach. New York. Academic Press.

Bieber, F.J. (1908). Das Hochl and von Sudathiopien. Petermann's Mitteilungenausjustus Perthes' GeographischerAnstalt 54: 1-15,99-114.

Bobbio, N. (1987). The Future of Democracy Minneapolis, University of Minnesota Press.

Borre, O. (2000) Critical Issues and Political Alienation in Denmark. Scandinavian Political Studies.

Bovensiepen, J. (2003). Social Exclusion and Marginalized Minorities: The Case of the Manjon in Sheka Society, Southwest Ethiopia. Bachelor Thesis at London University unpublished.

Burton, M. \& Kagan, C.(2003). Marginalization. Community Psychology: in Pursuit of Wellness Libration. Macmillan /palgrave, London.

Dalton, R. J. (2004). Democratic Challenges, Democratic Choices. The Erosion of Political Support in Advanced Industrial Democracies., Oxford Oxford University Press.

Dea, D.(2000). Social Discrimination and Poverty in IsseraGenaWoreda, South Ethiopia: AStudy Commissioned 
by Action-Aid Ethiopia. September, 2000.

DeSisto,F.(2014).'From Conflict Escalation to Conflict Transformation: Actual And Ethiopian Human Rights Council (2009).'Parallel Report Submitted to the Committee of RacialDiscrimination',pp.1-30.

FDRE Constitution (1995).'The Constitution of the Federal Democratic Republic of Ethiopia. Addis Ababa.

Flower, D. (1997). Striking a Balance: A Guide to Enhancing the Effectiveness of Ngos in International Development. London. Earth scan Publications Ltd.

Foster, G. M. (1972). The Anatomy of Envy: A Study of Symbolic Behavior. Current Anthropology.

Freeman, D. and Pankhurst, A. (2003). Understanding marginalization in Ethiopia. The Excluded Minorities of Ethiopia. London, UK.

Gamest, F.C.(1979). Way to Ways: Change from Hunting to Peasant Life. In Hess, R. (ed) Proceedings of the Fifth International Conference on Ethiopian Studies. Chicago University of llanos.

Gebreslassie Kiros (2016). Social Stratification and Marginalization in Southern Nations Nationalities and People Region of Ethiopia: The Case of Manja Minority Groups: Global Journals Inc. (USA).

Gezahegn Petros (2003). Kafa. In Freeman, D. \& A. Pankhurst (eds.), Peripheral People: the Excluded Minorities of Ethiopia. Asmara: The Red Sea Press, pp. 80-96.

Gore, C. (1994). Social exclusion and Africa south of the Sahara: A Review of Literature. Labor Institution and Development Program me. Review of the Literature. ILO Publication.

GudetaHailu.(2003) : Report on the Manja. Masha Woreda Council, Published.

Goul -Andersen, J. \& Hoff, J. (2001) Democracy and Citizenship in Scandinavia, New York Palgrave.

Listhaug, O. (1995). The Dynamics of Trust in Politicians. In Hans-Dieter Klingemann, D. F. (Ed.) Citizens and the State. Oxford, Oxford University Press.

Massaja, A. G. (1888). I mieitrentacinqueanni di missionenell'alta Etiopia: Memorie storiche. vol5. Roma: TipografiaPoliglotta\& Milano: Tip. Ponti£ S. Giuseppe.

MengistuSeyoum (2003). Shekacho. In Freeman, D. \&A. Pankhurst (eds.), Peripheral People: The Excluded Minorities of Ethiopia. Asmara: The Red Sea Press.

Miller, A. (1974) Political Issues and Trust in Government: 1964-1970. American Political Science Review, 68, 951-958.

Pankhurst, A. (1999) 'Caste' in Africa: The Evidence from South-Western Ethiopia. Reconstructed Africa 69 (4), 485-509.

Pankhurst, A. (2001)."Dimensions and Conceptions of Marginalization". Living on the Edge. Marginalized Minorities of Craft workers and Hunters in Southern Ethiopia. Addis Ababa: Department of Sociology and Administration, Addis Ababa University.

Svallfors, S. (2007). The Political Sociology of the Welfare State. Institutions, Social Cleavages and Orientations. Stanford, Stanford University Press.

Thompson, W. E. \& Horton, J. E. (1960). Political Alienation as a Force in Political Action. Social Forces, 38, 190-195.

Teshome,W.and Záhořík,J., (2008).Federalism in Africa: The Case of Ethnic-Based Federalism in Ethiopia.JournalofHumanSciences,5(2).

UNDP (2000).Human Development Report: Human Rights and Human Development. New York. Oxford University Press. 